JAMP: Jurnal Adminitrasi dan Manajemen Pendidikan

Volume 5 Nomor 1 Maret 2022, Hal : 17 - 24

Tersedia Online di http://journal2.um.ac.id/index.php/jamp/

ISSN 2615-8574 (online)

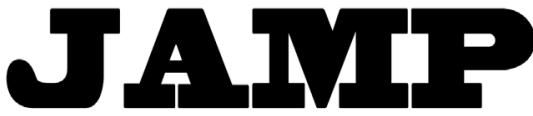

JURNAL ADMINISTRASI DAN MANAJEMEN PENDIDIKAN

\title{
PENGARUH KECAKAPAN LITERASI DIGITAL GURU TERHADAP PENGUATAN PENDIDIKAN KARAKTER SISWA SEKOLAH DASAR
}

\author{
Tasrif Akib, Fathrul Arriah, Surya Dharma
}

\author{
Universitas Muhammadiyah Makassar \\ Jl. Sultan Alauddin No.259, Gn. Sari, Kec. Rappocini, Kota Makassar, Sulawesi Selatan \\ E-mail: tasrifakib@unismuh.ac.id. No. HP 08114444499
}

\begin{abstract}
: this study is intended to know how teachers' digital literacy skills affect character education in the elementary school of the country in the city of makassar. The study involved a teacher's population of civil servants at the country's elementary school in the 589 city of makassar and was dispersed from 50 state elementary schools in the city of makassar. As for the number of research samples, as many as 85 teachers were obtained based on the slovin formula with a $10 \%$ tolerance limit. The random sampling technique is done in the acquiring of research samples. As for acquiring research data using the likeart scale questionnaires that test its validity using Gregory formulas and valiance tests of its build using technical additives factor analysis and using the alpha cronbach formula for an instrument that produces a 0.97 coefficient value of teachers 'digital literacy skills and a 0.97 coefficient value for a character education reinforcement instrument. The data analysis in the study USES the parametric statistical technique of simple regression analysis. Studies reveal that there is a positive and significant impact of a teacher's digital literacy skills on improving character education at the state elementary school in the city of makassar. Follow up on these research results then proficiency digital literacy must optimized.
\end{abstract}

Keywords: Digital literacy skills; Strengthening character education; Primary school

\begin{abstract}
Abstrak: Penelitian ini bertujuan untuk mengetahui pengaruh kecakapan literasi digital guru terhadap penguatan pendidikan karakter pada sekolah dasar negeri di kota Makassar. Penelitian ini melibatkan populasi guru berstatus pegawai negeri sipil pada sekolah dasar negeri di kota Makassar yang berjumlah 589 orang dan tersebar dari 50 Sekolah Dasar Negeri di Kota Makassar. Adapun jumlah sampel penelitian sebanyak 85 orang guru yang diperoleh berdasarkan rumus slovin dengan batas toleransi $10 \%$. Teknik purpose random sampling dilakukan dalam memeperoleh sampel penelitian. Adapun dalam memperoleh data penelitian menggunakan kuesioner skala likeart yang uji validitas isinya menggunakan formula gregory dan uji validitas konstruknya menggunkan teknik confirmatory factor analysis serta menggunakan rumus alpha cronbach dalam pengujian reabilitas instrumen yang menghasilkan nilai koefisien reabilitas 0,97 untuk instrumen kecakapan literasi digital guru dan nilai koefisien reabilitas 0,97 untuk instrumen penguatan pendidikan karakter. Analisis data dalam penelitian ini menggunakan teknik statistik parametrik yakni analisis regresi sederhana. Hasil penelitian mengungkapkan bahwa terdapat pengaruh positif dan signifikan kecakapan literasi digital guru terhadap penguatan pendidikan karakter pada sekolah dasar negeri di Kota Makassar. Menindaklanjuti hasil penelitian ini maka kecakapan literasi digital guru harus lebih dioptimalkan.
\end{abstract}

Kata kunci: Guru; Kecakapan literasi digital; Penguatan pendidikan karakter; Sekolah dasar

penguatan pendidikan karakter bagi siswa memiliki peran yang urgen dewasa ini karena perubahan sikap peserta didik sangat ditentukan oleh faktor eksternal yang diantaranya mencakup lingkungan budaya sekolah, kurikulum sekolah metode mengajar serta pendidik dan dalam memperkuat karakter siswa peran sentral gurulah yang paling dominan(Maisaro et al., 2018). Pendidikan karakter pada 
hakekatnya mengarah kepada pembentukan ahklah dan moral dengan tujuan untuk membentuk sikap serta kepribadian siswa agar menjadi individu yang baik bagi bangsa dan masyarakat (Suanto \& Nurdiyana, 2020).

Saat ini lingkungan peserta didik telah bersentuhan dengan dunia teknologi dan informasi sehingga pentingnya mengintegrasikan program penguatan pendidikan karakter dalam setiap rangkaian pembelajaran di era industri 4.0 dan merupakan sebuah keharusan yang harus dilakukan oleh guru, misalnya menambahkan unsur-unsur atau nilai-nilai pendidikan karakter sesuai dengan materi pelajaran yang diberikan. Perkembangan teknologi dan informasi saat ini dapat membantu sistem pembelajaran serta berkontribusi dalam penguatan pendidikan karakter, perkembangan tersebut dapat dimanfaatkan dalam memberikan edukasi yang membangun perkembangan anak usia di sekolah dasar dan tentunya program penguatan pendidikan karakter merupakan sebuah tantangan di era revolusi industri 4.0 saat ini (Bahri \& Wahdian, 2021).

Memperhatikan kondisi karakter masyarakat diera revolusi industri 4.0 khususnya para peserta didik yang tergerus oleh perkembangan zaman, maka penguatan pendidikan karakter merupakan sebuah program yang tepat (Nudin et al., 2020). Penguatan pendidikan karakter akan secara konsisten menjaga nilai-nilai karakter peradaban suatu bangsa ditengah perubahan sosial yang dinamis (Robiasih et al., 2021), dan disinilah seorang guru mengambil peran untuk tetap mengintegrasikan perkembangan teknologi dengan sebuah pendidikan yang tetap dapat membentuk karakter dan kepribadian peserta didik, hal tersebut dapat dilakukan dengan mengintegrasikannya dalam proses belajar mengajar baik itu secara tematik ataupun dalam mata pelajaran (Asen, 2019).

Untuk mengintegrasikan hal tersebut tentunya dibutuhkan kecakapan guru dalam mengelolah teknologi digital. (List et al., 2020) mengungkapkan bahwa kecakapan literasi digital merupakan sebuah sikap dan kompetensi penting bagi setiap individu dan merupakan keterampilan abad 21 yang seyogyanya terintegrasi dalam proses belajar mengajar disekolah. Tentunya dengan cakap berliterasi digital guru akan dapat mentrasfer pengalaman, pengetahuan kedalam proses belajar mengajar yang dilakukan (Falloon, 2020). Hasil penelitian terdahulu (Sadaf \& Gezer, 2020) mengungkapkan bahwa guru yang memiliki kecakapan literasi digital yang baik akan meningkatkan pemahaman dan wawasan siswa dalam materi pembelajaran yang disampaikan oleh guru.

Tentunya kecakapan literasi digital guru tidak sesederhana bahwa guru hanya perlu memahami teknologi dan informasi, melainkan bagaimana guru dengan siswa dapat membangun sebuah koneksi atau hubungan dengan menggunakan teknologi dalam penyajiannya agar pengalaman guru atau informasi guru dapat tersampaikan termasuk dalam memberikan penguatan karakter yang tersaji dalam materi yang disampaikan (Mujtahid et al., 2021). Namun lebih dari itu guru memiliki peran sentral dalam penguatan pendidikan karakter saat ini karena adanya fenomena perkembangan teknologi informasi yang menekakankan berbagai aspek teknologi digital, artificial intelligence dan lain sebagainya yang tentunya memiliki dampak bagi kepribadian setiap masyarakat khususnya peserta didik, misalnya adanya perilaku individualis (Kosim, 2020), bahkan (Basyaruddin \& Rifma, 2020) mengemukakan bahwa kemajuan teknologi informasi memberikan dampak terhadap pergeseran karakter peserta didik. Olehnya itu penguatan pendidikan karakter patutnya diintegrasikan dalam pembelajaran agar peserta didik tetap memperoleh Pendidikan sejati.

Berdasarkan hasil wawancara dengan beberapa guru sekolah dasar negeri di kota Makassar diungkapkan bahwa pihak sekolah dan guru telah melaksanakan semua aspek kegiatan yang terkait dengan program penguatan pendidikan karakter, namun sejak pandemi covid-19 mewabah dan diterbitkannya Surat Edaran oleh Kemdikbud No. 4 Tahun 2020 yang menganjurkan ditiadakan pembelajaran disekolah secara langsung sehingga penguatan pendidikan karakterpun dilaksanakan secara daring dengan mengintegrasikannya dalam mata pelajaran yang disajikan melalui berbagai platform digital. Kemudian (Shaleh \& Miswar, 2020) mengungkapkan dalam penelitiannya bahwa penguatan pendidikan karakter pada sekolah dasar menjadi perhatian utama bagi setiap pelaksana dan pemerhati pendidikan di situasi new normal saat ini, serta penelitian (Onde et al., 2020) yang menerangkan bahwa terdapat fenomena terkikisnya nilai moral dan karakter anak yang sangat memprihatinkan sebagai dampak dari revolusi 
industri 4.0. keterbukaan segala akses informasi memungkinkan setiap siswa menerima berbagai informasi yang dapat memperngaruhi bahkan merubah karakter siswa, sikap maupun cara berpikirnya yang tentunya ini menjadi tantangan bagi bidang Pendidikan di indonesia (Taufik, 2020).

Dalam upaya mengembangkan dan menumbuhkan karakter siswa pada sekolah dasar melalui penerapan pendidikan karakter merupakan sebuah tanggungjawab yang seyogyanya harus disadari oleh setiap elemen dibidang pendidikan secara kolektif khususnya bagi guru sebagai pendidik. Kesadaran akan penting dan urgennya hal tersebut akan sangat mempengaruhi kelancaran proses penguatan pendidikan karakter, serta pentinya menyiapkan generasi yang memiliki karakter unggul dan mampu menjawab tantangan dimasanya. Olehnya itu berdasarkan konteks tersebut dinilai perlunya dilakukan penelitian yang bertujuan untuk mengetahui pengaruh kecakapan literasi digital guru terhadap penguatan pendidikan karakter pada sekolah dasar.

\section{METODE}

Penelitian ini menerapkan pendekatan kuantitatif dengan menggunakan menggunakan metode survei yang dilaksanakan dari agustus - september 2021 pada sekolah dasar negeri di kota Makassar. Guru yang berstatus pegawai negeri sipil yang berjumlah 589 orang pada 50 sekolah dasar negeri di kota Makassar merupakan populasi dalam penelitian ini dan adapun jumlah sampel penelitian sebanyak 85 orang guru yang diperoleh berdasarkan rumus slovin dengan batas toleransi 10\%. Teknik purpose random sampling dilakukan dalam memperoleh sampel penelitian. Variabel bebas (X) yaitu kecakapan literasi digital guru dan variabel terikat (Y) yaitu penguatan pendidikan karakter yang desain penelitiannya disajikan pada gambar berikut :

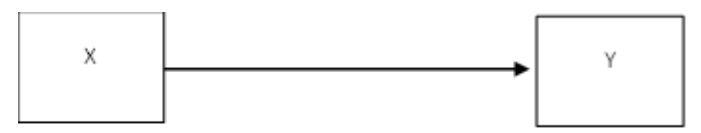

\section{Gambar. 1 Desain Penelitian}

Dalam memperoleh data penelitian mengunakan kuesioner skala likeart yang telah diuji validitas isinya menggunakan model pengujian gregory dan uji validitas konstruknya menggunakan confirmatory factor analysis (CFA) dengan metode maximum likelihood dan rumus alpha cronbach dalam pengujian reabilitasnya. Teknik analisis yang digunakan yaitu teknik regresi linear sederhana. Adapun bentuk persamaan regresinya yaitu $\hat{Y}=\beta 0+\beta 1 X+\varepsilon$. Adapun hipotesis dalam penelitian ini yaitu terdapat pengaruh positif yang signifikan kecakapan literasi digital guru terhadap penguatan pendidikan karakter pada sekolah dasar negeri di kota Makassar dengan $\alpha(5 \%)$.

\section{HASIL DAN PEMBAHASAN}

\section{Hasil Pengujian validitas isi}

Berdasarkan perhitungan uji validitas menggunakan formula gregory diperoleh hasil yang menunjukan koefisien konsistensi internal bernilai 1 dari 17 item yang dikembangkan untuk instrumen kecakapan literasi digital guru dan koefisien konsistensi internal bernilai 1 dari 20 item yang dikembangkan untuk instrumen penguatan pendidikan karakter. Berdasarkan peroleh tersebut, dikemukakan bahwa untuk setiap intrumen memperoleh nilai koefisien konsistensi internal $>0,75$ sehingga telah memenuhi syarat berdasarkan validitas isi.

\section{Hasil uji validitas konstruk}

Metode confirmatory factor analysis dengan pendekatan maximum likehood merupakan teknik dalam menguji validitas konstruk terhadap setiap instrumen dalam penelitian ini dengan kriteria Kaiser Meyer Olkin (KMO) dan Measure of Sampling Adequacy (MSA) bernilai > 0,50. Uji bartlett's tes memperoleh nilai sig.p 0,00 untuk analisis lebih lanjut, kemudian nilai anti image correlation $>0,50$ untuk diikutkan dalam analisis faktor, serta nilai factor loading $\geq 0,40$ (Azwar, 2019) yang perhitungannya menggunakan bantuan program SPSS for windows. 


\section{Instrumen kecakapan literasi digital guru}

Tabel 1. Hasil Pengujian KMO-MSA and Bartlett's Test

\begin{tabular}{cll}
\hline Kaiser-Meyer-Olkin Measure of Sampling Adequacy. & 0,90 \\
& Approx. Chi-Square & 2373.01 \\
Bartlett's Test of Sphericity & Df & 0,13 \\
& Sig. & 0,00 \\
\hline
\end{tabular}

Berdasarkan tabel.1 diatas diperoleh nilai KMO-MSA sebesar 0,90 serta sig. $p$ 0,00 sehingga menunjukan bahwa kecukupan sampel telah terpenuhi dalam melakukan analisis faktor. Selanjutnya diperoleh nilai anti image correlation $>0,50$ pada 5 Indikator dengan sebaran 17 item yang selanjutnya akan diikutkan dalam menentukan sebuah faktor dengan metode maximum likelihood sehingga diperoleh hasil sebagai berikut :

Tabel 2. Hasil Factor Matrix

\begin{tabular}{ll}
\hline & Factor \\
\cline { 2 - 2 } & $\mathbf{1}$ \\
\hline B1.I1 & .920 \\
B2.I1 & .899 \\
B3.I1 & .798 \\
B4.I2 & .779 \\
B5.I2 & .894 \\
B6.I2 & .895 \\
B7.I2 & .916 \\
B8.I3 & .647 \\
B9.I3 & .758 \\
B10.I3 & .944 \\
B11.I3 & .848 \\
B12.I4 & .612 \\
B13.I4 & .731 \\
B14.I4 & .857 \\
B15.I5 & .801 \\
B16.I5 & .818 \\
B17.I5 & .826 \\
\hline
\end{tabular}

Berdasarkan tabel diatas menunjukan bahwa 17 item dari 5 indikator memiliki nilai factor loading $>0,40$ sehingga hasil analisis menunjukan bahwa semua butir yang memiliki nilai factor loading $>$ 0,40 terdapat pada 5 indikator sebagai variabel teramati telah memberikan sumbangan berarti untuk mengukur variabel laten pada penelitian ini serta di peroleh nilai goodness of fit test dimana nilai chi square sebesar 765,98 dan sig. $p$ bernilai 0,00 .

\section{Instrument penguatan Pendidikan karakter}

Tabel 3. Hasil Pengujian KMO-MSA and Bartlett's Test

\begin{tabular}{cll}
\hline Kaiser-Meyer-Olkin Measure of Sampling Adequacy. & 0,90 \\
& Approx. Chi-Square & 2664.40 \\
Bartlett's Test of Sphericity & Df & 0,13 \\
& Sig. & 0,00 \\
\hline
\end{tabular}


Berdasarkan tabel diatas diperoleh nilai $K M O-M S A$ sebesar 0,87 serta sig.p 0,00 sehingga menunjukan bahwa kecukupan sampel telah terpenuhi dalam melakukan analisis faktor. Selanjutnya diperoleh hasil bahwa pada 10 indikator dengan sebaran 17 item memiliki nilai anti image correlation $>0,50$ dari 20 item yang dikembangkan yang selanjutnya 17 item tersebut akan diikutkan dalam menentukan sebuah faktor dengan metode maximum likelihood sehingga diperoleh hasil sebagai berikut:

Tabel 4. Hasil Factor Matrix

\begin{tabular}{ll}
\hline & Factor \\
\cline { 2 - 2 } & $\mathbf{1}$ \\
\hline B1.I1 & .898 \\
B2.I1 & .848 \\
B4.I2 & .723 \\
B5.I3 & .863 \\
B6.I3 & .865 \\
B7.I4 & .929 \\
B9.I5 & .763 \\
B10.I5 & .945 \\
B11.I6 & .861 \\
B13.I7 & .736 \\
B14.I7 & .874 \\
B15.I8 & .815 \\
B16.I8 & .810 \\
B17.I9 & .812 \\
B18.I9 & .802 \\
B19.10 & .967 \\
B20.10 & .971 \\
\hline
\end{tabular}

Berdasarkan tabel diatas menunjukan bahwa 17 item dari 10 indikator memiliki nilai factor loading $>0,40$ sehingga hasil analisis menunjukan bahwa semua butir yang memiliki nilai factor loading $>$ 0,40 terdapat pada 10 indikator sebagai variabel teramati telah memberikan sumbangan berarti untuk mengukur variabel laten pada penelitian ini serta di peroleh nilai good of fit test dimana nilai chi square sebesar 752,59 dan sig. $p$ bernilai 0,00

\section{Hasil Uji Reabilitas}

Tabel 5. Hasil Uji Reabilitas

\begin{tabular}{ccl}
\hline \multicolumn{1}{c}{ Instrumen } & Nilai & Keterangan \\
\hline Kecakapan Literasi digital guru & 0,97 & Reliabel \\
Penguatan Pendidikan karakter & 0,97 & Reliabel \\
\hline
\end{tabular}

Hasil perhitungan denganrumus cronbach alpha berbantuan program SPSS for windows diperoleh bahwa kedua instrumen pada penelitian ini memiliki nilai koefisien reabilitas bernilai 0,97 untuk instrumen kecakapan literasi digital guru dan nilai koefisien reabilitas untuk instrumen penguatan Pendidikan karakter bernilai 0,97 sehingga kedua instrument pada penelitian ini telah memenuhi syarat reabilitas $>0,75$.

\section{Hasil Pengujian Hipotesis}

Data yang telah diperoleh berdasarkan pengumpulan data yang telah dilakukan selanjutnya dianalisisdengan teknik analisis regresi sederhana dalam mencapai tujuan penelitian menggunakan bantuan program SPSS for windows. Berikut disajikan hasil analisis tersebut : 
Tabel 6. Coefficients

\begin{tabular}{cllllll}
\hline Model & & Unstandardized Coefficients & $\begin{array}{l}\text { Standardizerd } \\
\text { Coefficients }\end{array}$ & t & Sig \\
\cline { 3 - 5 } & & B & Std, error & Beta & \\
\hline \multirow{2}{*}{1} & (Constant) & 27.54 & 5.01 & & 5,48 & 0,00 \\
& LD & 0.53 & .003 & 0,57 & 6,43 & 0,00 \\
\hline
\end{tabular}

Pada tabel.6 coefficien diperoleh bentuk persamaan regresi pada penelitian ini yaitu dimana konstanta $\beta 0$ bernilai 27,54 dan koefisien regresi $\beta 1$ bernilai 0,53 sehingga model persamaan regresi yang terbentuk yaitu $Y ́=27,54+0,53$ yang dapat diartikan bahwa jika penguatan pendidikan karater diperkirakan akan meningkan sebesar 0,53 untuk setiap peningkatan literasi digital guru sebesar satu skor. Kemudian untuk arah hubungan antar variabel dalam penelitian ini disajikanpada tabel berikut:

Tabel 7. Model Summary

\begin{tabular}{lrlll}
\hline Model & R & R Square & Adjust R Square & Std. Error of the Estimate \\
\hline 1 & $0,57 \mathrm{a}$ & 0,33 & 0,32 & 3,73 \\
\hline
\end{tabular}

a.Predictors: (Contant), LD

Dari tabel diatas diperoleh hasil hitung koefisien bernilai 0,57 yang menunjukan arah positif, selanjutnya berdasarkan pengujian signifikansi yang dilakukan diperoleh nilai sig.p $(0,00)<\alpha(0,05)$ atau nilai $t$ hitung $(6,43)>\mathrm{t}$ tabel $(1,66)$ sehingga dapat dikemukakan bahwa Ho ditolak dan H1 diterima dalam penelitian ini. Dugaan yang menyatakan terdapat pengaruh yang positif dan signifikan kecakapan literasi digital guru terhadap penguatan pendidikan karakter pada sekolah dasar negeri di kota Makassar terbuktidalam penelitian ini. Selanjutnya diperoleh nilai koefisien determinasi $\left(\mathrm{R}^{2}\right)$ dengan besaran 0,33 atau 33\% yang menjelaskan bahwa sebesar 33\% kecakapan literasi digital guru (X) berkontribusi terhadap penguatan pendidikan karakter atau dapat pula diterangkan bahwa 33\% variansi yang terjadi dalam penguatan pendidikan karakter $(\mathrm{Y})$ terjelaskan oleh kecakapan literasi digital guru(X) dan sebesar $67 \%$ dapat ditentukan oleh faktor lain.

Berdasarkan pengolahan data yang telah dilakukan, terungkap dalam penelitian ini jika terdapat pengaruh positif yang signifikan kecakapan literasi digital guru terhadap penguatan pendidikan karakter pada sekolah dasar negeri di kota Makassar. Hal tersebut ditunjukan berdasarkan nilai koefisien regresi yang menunjukan nilai positif dan signifikan sehingga dapat diterangkan bahwa pengaruh kecakapan literasi digital guru berkontribusi nyata terhadap penguatan pendidikan karakter. Kontribusi tersebut dapat dimaknai semakin baik kecakapan literasi digital guru maka akan semakin baik atau semakin meningkatkan penguatan pendidikan karakter siswa di sekolah dasar.

Adanya penemuan dalam penelitian ini yang menerangkan bahwa terdapat pengaruh positif dan signinifikan kecakapan literasi digital guru terhadap penguatan pendidikan karakter, sejalan dengan temuan dalam sebuah penelitian yang dilakukan (Apriani et al., 2021) yang mengungkapkan bahwa dalam penguatan pendidikan karakter dalam situasi pandemi covid-19 atau new normal dimana guru melakukan berbagai macam metode yang salah satunya ialah menggunakan perangkat digital secara virtual atas kerjasama dan dukungan orangtua siswa dan guru, melalui pengunaan perangkat digital dapat membentuk karakter mandiri peserta didik yakni tidak bergantung pada orang lain dan adanya kesadaran dalam belajar secara mandiri, dimana karakter mandiri ini merupakan salah satu indikator dalam penguatan pendidikan karakter. Kemudian (Ahmadi et al., 2017) mengungkapkan bahwa media pembelajaran berbasis multimedia digital adalah sebuah alternatif yang tepat dalam mengoptimalkan kualitas pendidikan khusus penguatan pendidikan karakter disekolah dasar.

Dalam penguatan pendidikan karakter yang pelaksanaan teknisnya salah satunya ialah berbasis budaya sekolah dimana adanya kegiatan literasi digital (Daryanto \& Karim, 2017) sebagai bagian dari pengembangan pendidikan karakter peserta didik dalam menghadapi tantangan pendidikan abad 21 . (Zidniyati, 2019) mengungkapkan bahwa peran utama pendidikan diera revolusi industri 4.0 dengan menguatkan pendidikan karakter para generasi dalam hal ini peserta didik melalui lingkungan belajar 
yang diciptakan oleh para pendidik, tentunya pada era digital saat ini guru memiliki peranan yang sangat penting dalam membentuk karkater peserta didik yang salah satunya dapat di integrasikan dalam sebuah mata pelajaran dan mengaitkannya dengan norma-norma dengan kehidupan sehari-hari (Putri, 2018).

Dewasa ini sudah sebaiknya setiap instansi pendidikan khususnya para pendidik mulai menerapkan pembiasaan literasi digital yang mengintegrasikan pendidikan karakter dalam setiap pembelajaran agar terbangun dan terbentuk karakter peserta didik modern dalam rangka menghadapi tantangan pendidikan abad 21 dan era disrupsi teknologi agar tidak tergerus dengan arus perkembangan teknologi. Apabila seorang insan dalam hal ini peserta didik cakap dalam hal kognitif dan moral maka akan baik pula masa depan bangsa tersebut, olehnya itu peran guru sebagai bagian dari sebuah institusi pendidikan mempunyai tanggungjawab untuk menciptakan generasi yang berakhlak dan bermoral.

\section{SIMPULAN DAN SARAN}

\section{Simpulan}

Dalam penelitian ini terungkap bahwa terdapat pengaruh positif yang signifikan kecakapan literasi digital guru terhadap penguatan pendidikan karakter pada sekolah dasar negeri di kota Makassar. Terungkap pula bahwa dari model persamaan regresi yang terbentuk yakni Ý $=27,54+0,53$ mampu menerangkan bahwa jika penguatan pendidikan karakter diperkirakan meningkat sebesar 0,53 untuk setiap peningkatan kecakapan literasi digital guru sebesar satu skor, hal tersebut bermakna jika semakin baik kecakapan literasi digital guru maka akan semakin baik atau semakin meningkatkan penguatan pendidikan karakter siswa. Diterangkan pula bahwa sebesar 33\% kecakapan literasi digital guru berkontribusi terhadap penguatan pendidikan karakter.

\section{Saran}

Disarankan beberapa hal dalam penelitian ini yaitu : 1) teruntuk dinas pendidikan kota Makassar untuk lebih banyak memberikan pelatihan maupun program-program yang dapat lebih meningkatkan kecakapan literasi digital guru sekolah dasar, 2) bagi guru sekolah dasar di kota Makassar diharapkan mengintegrasikan program penguatan pendidikan karakter pada setiap mata pelajaran yang di integrasikan dengan perkembangan teknologi informasi. 3) Hasil penelitian ini dapat menjadi sebuah referensi data bagi pemerintah dalam membuat kebijakan dibidang pendidikan yang sejalan dengan perkembangan teknologi informasi.

\section{DAFTAR RUJUKAN}

Ahmadi, F., Witanto, Y., \& Ratnaningrum, I. (2017). Pengembangan Media Edukasi "Multimedia Indonesian Culture" (Mic) Sebagai Penguatan Pendidikan Karakter Siswa Sekolah Dasar. Jurnal Penelitian Pendidikan, 34(2), 127-136. https://doi.org/10.15294/jpp.v34i2.12368

Apriani, A., Suwandi, I. K., Ariyani, Y. D., \& Sari, I. P. (2021). Penguatan Pendidikan Karakter pada Masa New Normal Covid-19 melalui Flipped Classroom Strengthening Character Education in New Normal Covid-19 Periode through Flipped Classroom. Jurnal Penelitian dan ilmu pendidikan, 14(2), 102-113. https://doi. org/10.21831/jpipfip.v14i1.37909

Asen, A. (2019). Upaya Meningkatkan Ketrampilan Guru Dalam Mengimplementasikan PPK (Penguatan Pendidikan Karakter) Melalui Metode Pembiasaan Kultur Di SDN-1 Sagu Sukamulya. Suluh: Jurnal Bimbingan dan Konseling, 5(1), 1-5. https://doi.org/10.33084/suluh.v5i1.1097

Azwar, S. (2019). Reabilitas dan validitas. Yogyakarta: Pustaka Pelajar.

Bahri, S., \& Wahdian, A. (2021). Penguatan Nilai-Nilai Pendidikan Karakter Melalui Game Edukasi Icando di Sekolah Dasar. Jurnal Pendidikan Dasar Nusantara, 6(2), 23-41. https://doi.org/10.29407/jpdn.v6i2.15078

Basyaruddin, N. Y., \& Rifma, R. (2020). Evaluasi Penguatan Pendidikan Karakter. JMKSP (Jurnal Manajemen, Kepemimpinan, dan Supervisi Pendidikan), 5(1), 4. https://doi.org/10.31851/jmksp.v5i1.3498

Daryanto, \& Karim, S. (2017). Pembelajaran abad 21. Yogyakarta: Penerbit Gava media.

Falloon, G. (2020). From digital literacy to digital competence: the teacher digital competency (TDC) framework. Educational Technology Research and Development, 68(5), 2449-2472. https://doi.org/10.1007/s11423-02009767-4 
Kosim, M. (2020). Penguatan Pendidikan Karakter di Era Industri 4.0: Optimalisasi Pendidikan Agama Islam di Sekolah. TADRIS: Jurnal Pendidikan Islam, 15(1), 88. https://doi.org/10.19105/tjpi.v15i1.2416

List, A., Brante, E. W., \& Klee, H. L. (2020). A framework of pre-service teachers' conceptions about digital literacy: Comparing the United States and Sweden. Computers and Education, 148(January), 103788. https:// doi.org/10.1016/j.compedu.2019.103788

Maisaro, A., Wilyono, B., \& Arifin, I. (2018). Manajemen Program Penguatan Pendidikan Karakter. Jurnal Administrasi dan Manajemen Pendidikan, 1(September), 302-312. https://doi.org/10.17977/ um027v1i32018p302

Mujtahid, I. M., Berlian, M., Vebrianto, R., Thahir, M., \& Irawan, D. (2021). The Development of Digital Age Literacy: A Case Study in Indonesia. Journal of Asian Finance, Economics and Business, 8(2), 1169-1179. https://doi.org/10.13106/jafeb.2021.vol8.no2.1169

Nudin, B., Prayesti, T., Suratiningsih, S., \& Dwi Novianty, W. (2020). Manajemen Gerakan Sekolah Menyenangkan dalam Penguatan Pendidikan Karakter (PPK) di SD Negeri Buayan Kebumen. MANAGERIA: Jurnal Manajemen Pendidikan Islam, 5(1), 95-118. https://doi.org/10.14421/manageria.2020.51-06

Onde, M. L. ode, Aswat, H., B, F., \& Sari, E. R. (2020). Integrasi Penguatan Pendidikan Karakter (Ppk) Era 4.0 Pada Pembelajaran Berbasis Tematik Integratif Di Sekolah Dasar. Jurnal Basicedu, 4(2), 268-279. https:// doi.org/10.31004/basicedu.v4i2.321

Putri, D. P. (2018). Pendidikan Karakter Pada Anak Sekolah Dasar Di Era Digital. AR-RIAYAH : Jurnal Pendidikan Dasar, 2(1), 37-50. https://doi.org/10.29240/jpd.v2i1.439

Robiasih, H., Setiawan, A., \& Dardjito, H. (2021). Character education strengthening model during learning from home: Ki Hajar Dewantara's scaffolding concept. Jurnal Penelitian dan Evaluasi Pendidikan, 25(1), $25-34$. https://doi.org/10.21831/pep.v25i1.36385

Sadaf, A., \& Gezer, T. (2020). Exploring factors that influence teachers' intentions to integrate digital literacy using the decomposed theory of planned behavior. Journal of Digital Learning in Teacher Education, 36(2), 124-145. https://doi.org/10.1080/21532974.2020.1719244

Shaleh, M., \& Miswar. (2020). Urgensi pendidikan akhlak bagi anak usia dasar. Jurnal Taskiya, 9(2), 92-107.

Suanto, \& Nurdiyana. (2020). Evaluasi Implementasi Peraturan Presiden No.87 Tahun 2017 tentang Penguatan Pendidikan Karakter. Jurnal Pendidikan Kewarganegaraan, 7(2), 107-114. https://doi.org/10.32493/jpkn. v7i2.y2020.p79-86

Taufik, M. (2020). Strategic Role of Islamic Religious Education in Strengthening Character Education in the Era of Industrial Revolution 4.0. Jurnal Ilmiah Islam Futura, 20(1), 86. https://doi.org/10.22373/jiif.v20i1.5797

Zidniyati. (2019). Penguatan Pendidikan Karakter di Sekolah Dasar di Era Revolusi Industri 4.0. Tarbiyatuna : Kajian Pendidikan Islam, 3(1), 41. https://doi.org/10.29062/tarbiyatuna.v3i1.199 